\title{
The flora of renal haemodialysis shunt sites
}

\author{
M. H. REBEL, R. VAN FURTH, P. STEVENS, LUCY BOSSCHER-ZONDERMAN, \\ AND W. C. NOBLE
}

From the University Hospital, Leiden, The Netherlands, and St John's Hospital for Diseases of the Skin, London

SYNOPSIS During investigations of the microbial flora of the skin over haemodialysis shunt sites it has not proved possible to predict clinical infection by a preceding colonization of the shunt site with a pathogenic organism. The normal non-pathogenic flora of the sites is not specifically related to the flora of other sites on the body though Staphylococcus aureus on a shunt site appeared to be acquired principally from the nose when the shunt was in the arm or from the perineum when the shunt was in the leg. Cimino shunt sites had a greater density of organisms than did Scribner shunt sites; this may be related to the disinfection procedures.

\begin{abstract}
Shunt site infections occurring in patients on routine haemodialysis are frequently due to Staphylococcus aureus or 'Staph. albus' and such infection may necessitate revision of the shunt or, occasionally, result in septicaemia, pulmonary embolism, or endocarditis (Public Health Laboratory Service, 1968; Goodman, Crews, Ginn, and Koenig, 1969; McIntosh, Petrie, and MacLeod, 1969; Levi, Robson, and Rosenfeld, 1970; Rao, Webster, Sunderland, Smith, Ampalam, and Lee, 1972). The question as to whether shunt site colonization precedes infection, seems not to have been asked; such colonization, if detected, might enable infection to be prevented. This paper records observations and investigations in a dialysis unit of the University Hospital of Leiden.
\end{abstract}

\section{Methods}

Patients undergoing routine, twice weekly dialysis were studied. Investigations were carried out in two phases.

In phase I (1970), patients were examined once a week. The nose, perineum, and skin around the shunt site were sampled using cotton-tipped swabs moistened with broth. Staff members were swabbed in the nose only. When it was not possible to inoculate the swabs directly onto growth media, they were stored overnight in Stuart's transport medium. Swabs were inoculated onto blood agar and examined principally for Staph. aureus and other common pathogens such as Pseudomonas and Proteus species. All Staph. aureus strains from this phase were phage typed.

Received for publication 16 July 1974 .
In phase II (1972), the nose, gums, chest, perineum, axillae, toe webs, and shunt site were examined once only. Swabs were inoculated directly onto blood agar (aerobic and anaerobic incubation), McConkey, CLED, and Sabouraud agar. All except the Sabouraud plates were incubated at $37^{\circ} \mathrm{C}$ for $24 \mathrm{hr}$ and then at bench temperature for a further 24 hours. One Sabouraud plate was incubated at $37^{\circ} \mathrm{C}$ for one week, the other at about $30^{\circ} \mathrm{C}$ for two weeks or more. All organisms were identified to the generic level; coagulase-negative cocci were identified using the scheme reported by Baird-Parker (1963) and diphtheroids by the scheme reported by Somerville (1973).

Clinical notes were used to compile a record of infections from 1968 to 1972.

\section{Results}

Table I shows the number of patients diagnosed clinically during 1968 to 1972 as having a shunt infection and the principal infecting organism was recorded. Some patients suffered no apparent infection and another had repeated episodes of infection. Frequently one organism predominated in swabs from patients with repeated infection though others yielded a variety of organisms; table II shows illustrative histories from two patients in 1972.

During the phase I investigations, 32 patients were sampled each week for a period of four months; at this period most of the patients had Scribner shunts. A total of $\mathbf{4 4 2}$ samples was collected, a mean of about 14 samples per patient. On a few occasions the shunt site was not examined by us as infection had been diagnosed by the clinician in charge of the 


\begin{tabular}{|c|c|c|c|c|c|c|}
\hline & \multicolumn{4}{|c|}{ Principal Infecting Organisms } & \multirow[t]{2}{*}{ Not Swabbed } & \multirow{2}{*}{$\begin{array}{l}\text { Total } \\
\text { Patients } \\
\text { Dialysed }\end{array}$} \\
\hline & Staph. aureus & Staph.albus & 'Other' & 'Sterile' & & \\
\hline 1968 & 8 & 2 & 5 & 5 & 0 & 26 \\
\hline 1969 & 8 & 2 & 1 & 3 & 4 & 34 \\
\hline 1970 & 10 & 1 & 0 & 0 & 1 & 32 \\
\hline 1971 & 4 & 3 & 1 & 2 & 0 & 26 \\
\hline 1972 & 4 & 4 & 2 & 1 & $\mathbf{0}$ & 28 \\
\hline
\end{tabular}

Table I Number of patients with infected shunt sites

'Other' infecting organism included enterococci, Enterobacter sp., and Klebsiella sp.

patient and a swab already sent to the routine bacteriology laboratory.

The figure shows the results from phase I. There were 18 occasions when colonization of the skin around the shunt by Staph. aureus was found. Nine of these weekly colonizations were with strains carried in the nose of the patient and one further strain was carried in the perineum. In the remaining eight the strain could not be traced to the index patient or any other patient, although three might have been acquired from a member of the nursing staff who carried a similar strain in her nose.

In addition to the episodes of colonization, there were nine occasions when the clinician diagnosed infection (all due to Staph. aureus) on the appearant्छ of the skin and the presence of pus around the shunis One infection was with a Staph. aureus strain of the same phage type as carried in the patient's noseृ four infections were with Staph. aureus strains nef carried by the patient although three might have been acquired from a staff member. Regrettably the remaining four strains of Staph. aureus processed in the routine laboratory were not available for phage typing.

Ten of these 32 patients were frequent nasad carriers of Staph. aureus and suffered 15 of thet colonizations and five of the infections. Shunt colonization or infection appeared to be sporade

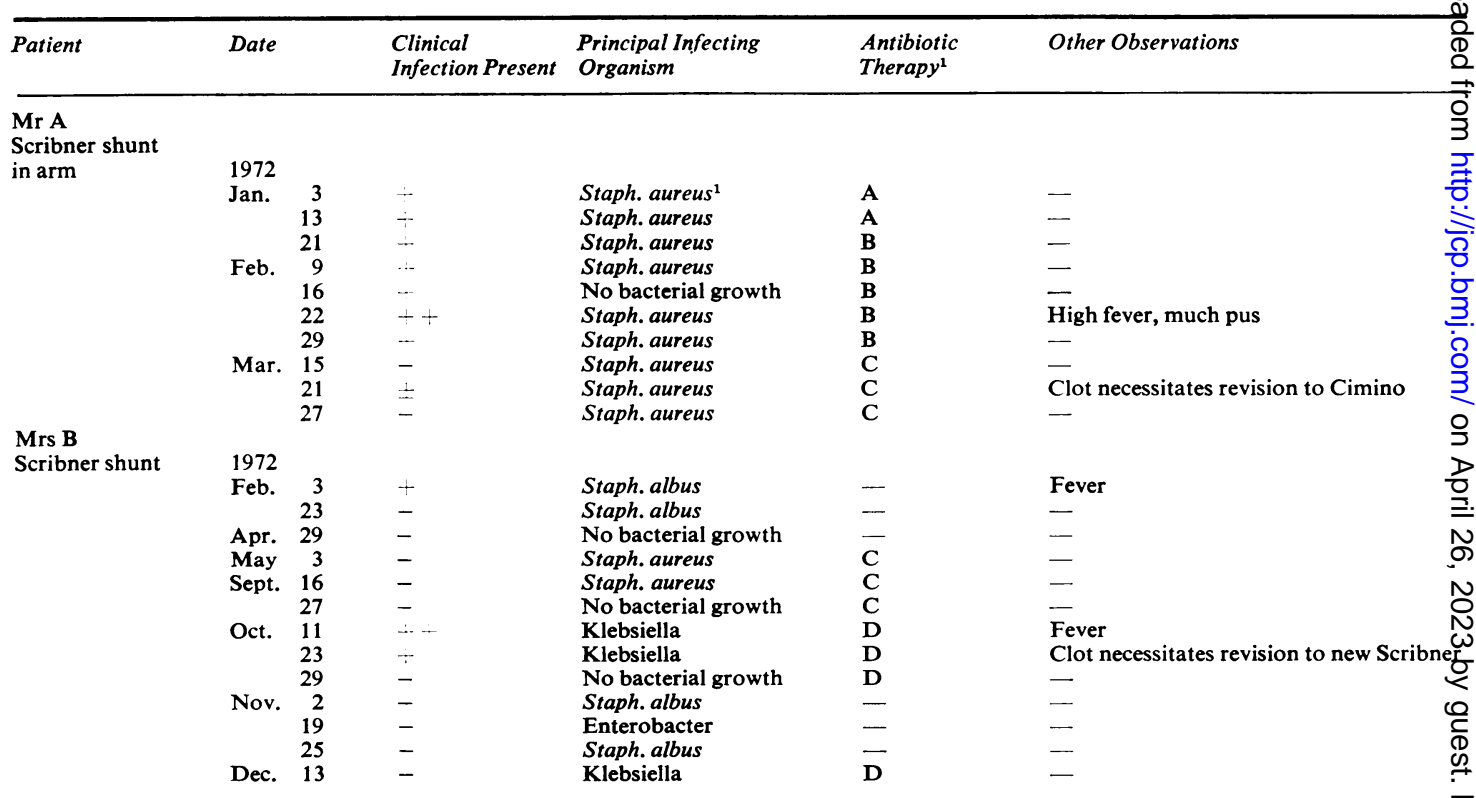

\section{Table II Illustrative histories of two patients with clinically apparent shunt infection}

\footnotetext{
${ }^{1}$ All Staphylococcus aureus strains from Mr A were resistant to penicillin, tetracycline, streptomycin, and sulphonamide, but sensitive to chloramphenicol, kanamycin, gentamicin, and methicillin.

${ }^{2} A$ Doxycyclin $1 \times 100 \mathrm{mg} /$ day plus gentamicin $40 \mathrm{mg}$ after dialysis

B Gentamicin $40 \mathrm{mg}$ after dialysis

C Cloxacillin $4 \times 1 \mathrm{~g}$

D Doxycyclin $1 \times 100 \mathrm{mg} /$ day
} 


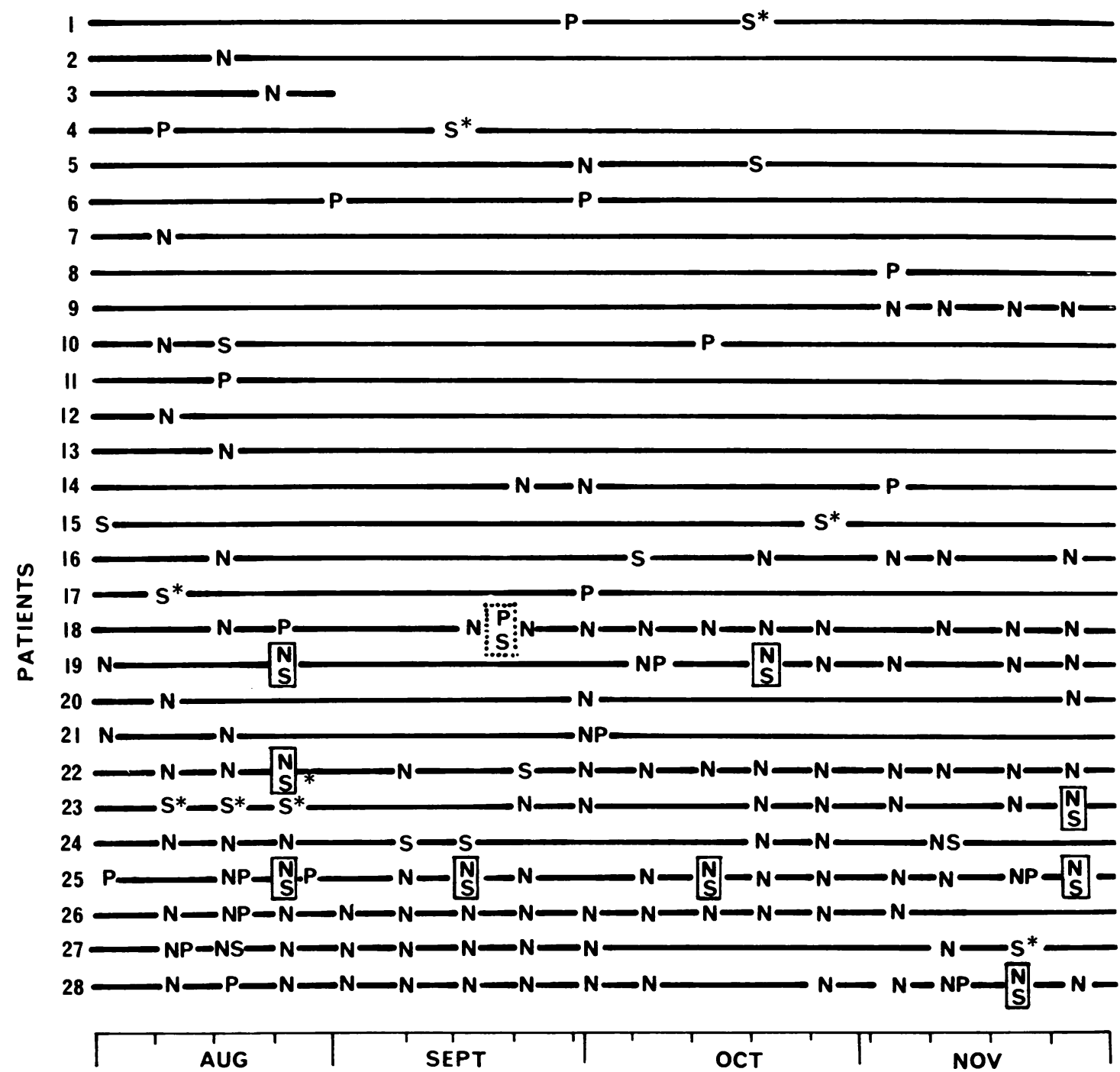

Fig Colonization of the nose, perineum, and shunt during phase I. Four patients who apparently never carried Staph. aureus have been omitted from this chart.

$\mathbf{N}=$ nasal colonization with Staph. aureus

$\mathbf{P}=$ perineal colonization with Staph. aureus

$\mathrm{S}=$ shunt colonization with $\mathrm{Staph}$. aureus

$\mathrm{S}^{*}=$ clinical infection of the shunt with Staph. aureus

$\mathbf{N}$
$\mathbf{S}$ = Staph. aureus of same phagetype isolated

and there was no evidence from this investigation that shunt colonization preceded clinically apparent infection.

During the phase II investigations, 23 patients were sampled once only. Five patients failed to yield any viable organisms from swabs around the shunt site (no other site failed to yield a reasonable 2 number of organisms) and nine yielded fewer than five colonies of diphtheroids or coagulase-negative cocci (table III). Four of the remaining nine shunt sites yielded Staph. aureus; in two instances this was also found in the nose, in one instance in the perineum (scanty Staph. aureus round a Scribner shunt in the leg), and the remaining patient yielded Staph. aureus 


\begin{tabular}{lllll}
\hline Shunt & $\begin{array}{l}\text { NoGrowth } \\
\text { or Scanty } \\
\text { Non-pathogens } \\
\text { Only }\end{array}$ & $\begin{array}{l}\text { Scanty } \\
\text { Pathogens }\end{array}$ & $\begin{array}{l}\text { Heavy Growth } \\
\text { Non-pathogens }\end{array}$ & $\begin{array}{l}\text { Heavy Prowth } \\
\text { Pathogens }\end{array}$ \\
\hline Scribner & 11 & 1 & 4 & 0 \\
Cimino & 3 & 0 & 0 & 4 \\
Total & 14 & 1 & 4 & 4 \\
\hline
\end{tabular}

Table III Distribution of organisms according to type of shunt in phase II

'Pathogens' include Staph. aureus and Citrobacter sp. Non-pathogens are principally coagulase negative, Gram-positive cocci and diphtheroids.

from the nose, axilla, and perineum. One patient yielded large numbers of Citrobacter sp. from the skin over a Cimino shunt in the arm and this organism was also found in the patient's axilla. One of the four remaining patients yielded large numbers of coagulase-negative cocci (staphylococci of BairdParker (1963) type S5 and S6 and micrococci of type M2), organisms of the same type being found elsewhere on the body; two yielded predominantly diphtheroids and the last a mixture of cocci and diphtheroids. No relationship could be found between the non-pathogenic flora of the shunt sites and other sites on the body.

During phase II, 16 patients had Scribner shunts and seven Cimino shunts. Scribner shunt sites were routinely disinfected with an iodine compound, whilst the skin over Cimino shunts was treated with chlorhexidine in alcohol. This is probably reflected in the flora of the shunt sites for the only sites to carry large numbers of organisms were those over Cimino shunts (table III).

\section{Discussion}

Staphylococcus aureus is the most frequently reported pathogen of haemodialysis shunt sites (Eykyn, Phillips, and Evans, 1970; Levi et al, 1970; Sherrard, 1970; Rao et al, 1972) and was found to be endemic in the investigations reported here. There was no evidence from the phase I investigations that colonization of the shunt preceded clinical infection, at least within the limitations set by swabbing once a week. There was a suggestion that one staff member carried strain of Staph. aureus responsible for some of the infections, though the phage pattern (group III) was too broad and the antibiotic sensitivity pattern (resistant to penicillin only) too common to make this certain. Since these dialysis patients lived at home except for the two weekly visits to the Unit at night, it is probable that family contacts accounted for some of the untraced strains.

Patients who were nasal or perineal carriers of Staph. aureus seemed predisposed to colonization and infection of the shunt site, and in a situation of severe endemic shunt infection, suppression of the्लि nasal or perineal flora might prove of value.

In phase II those patients with an apparentlo normal skin flora of cocci and diphtheroids at the shunt site carried the same organisms elsewhere of the body, often at multiple sites, and it was nof possible to identify any special area as contributing to the organisms around the shunt. Banks, Yate $\vec{b}$ Cawdrey, Harries, and Kidner (1970) in a study of infection of intravenous catheters also failed to fing a correlation between the normal skin flora and organisms infecting the catheter sites.

Patients whose skin over the shunt site waso heavily colonized with potential pathogens were also nasal or axillary carriers of the strains; all had Cimino shunts in the arm. There were five patiento with Scribner shunts in the arm, none of whom had heavily colonized skin around the shunt. The 1 t Scribner shunts in the leg included four with normal non-pathogenic flora of cocci and dip通 theroids around the shunt. Differences in the degree of colonization can probably be attributed t\& differences in the disinfection technique, for the iodine compounds might be expected to persist of the skin and prevent any luxuriant growth of organisms. It remains possible, however, that tho occurrence of an arteriovenous fistula results in $\frac{\mathscr{0}}{\mathrm{*}}$ higher temperature and humidity at the skin surface thus favouring the growth of microorganisms.

We are deeply indebted to the nursing staff of the Dialysis Unit for their cooperation. The technicid assistance of Miss E. Guley and Miss I. Smith gratefully acknowledged.

References

Baird-Parker, A. C. (1963). A classification of micrococci an staphylococci based on physiological and biochemical tests J. gen. Microbiol., 30, 409-427.

Banks, D. C., Yates, D. B., Cawdrey, H. M., Harries, M. G., an Kidner, P. H. (1970). Infection from intravenous catheters Lancet, 1, 443-445.

Eykyn, S., Phillips, I., and Evans, J. (1970). Vancomycin for staph lococcal shunt site infections in patients on regular haempo dialysis. Brit. med. J., 3, 80-82.

Goodman, J. S., Crews, H. D., Ginn, H. E., and Koenig, M. G. (1969ì. Bacterial endocarditis as a possible complication of chrone hemodialysis. New Engl. J. Med., 280, 876-877.

Levi, J., Robson, M., and Rosenfeld, J. B. (1970). Septicaemia and pulmonary embolism complicating use of arteriovenous fistu in maintenance haemodialysis. Lancet, 2, 288-290.

McIntosh, C. S., Petrie, J. C., and MacLeod, M. (1969). Maintenan of silastic-teflon shunts for intermittent-haemodialysis. Br@
med. J., 4, 717-720.

Public Health Laboratory Service (1968). Infection risks of haemo dialysis-some preventive aspects. (Report by Working Partrit on Haemodialysis Units). Brit. med. J., 3, 454-460.

Rao, R., Webster, A. B. D., Sunderland, D. R., Smith, W. FD Ampalam, S., and Lee, H. A. (1972). Cloxacillin and sodiug fusidate in management of shunt infections. Brit. med. J., 618-619.

Sherrard, D. J. (1970). Infections in haemodialysis patients. Lancet, 880.

Somerville, D. A. (1973). A taxonomic scheme for aerobic diphtheroif from human skin. J. med. Microbiol., 6, 215-224. 